\title{
LAS PERCEPCIONES DE LA INSEGURIDAD EN RELACIÓN CON LAS NOTICIAS DELICTIVAS: UN ANÁLISIS DESDE LA RECEPCIÓN*
}

\section{Perceptions of Insecurity on Criminal News: an Analysis from the Reception}

As perceções da insegurança em relação com as notícias delituosas: uma análise desde a receção

Brenda Focás, Instituto de Altos Estudios Sociales - Universidad Nacional de San Martín/ Conicet, Argentina

bfocas@gmail.com

Recibido: 20 de octubre de 2016

Aprobado: 4 de enero de 2018

\section{RESUMEN}

Los medios de comunicación -específicamente la televisión - son señalados como uno de los responsables de la creciente inquietud por la inseguridad. Se sostiene que exageran en la enunciación de las noticias policiales, que tienen intereses o intenciones en generar miedo, que son sensacionalistas. Pero ¿cómo interpretan los sujetos a los medios cuando representan 'la inseguridad' y cómo decodifican esta información? ¿Qué lugar ocupan las noticias

* Agradezco los comentarios y sugerencias de los evaluadores anónimos, que lograron mejorar la argumentación y la claridad de este artículo. 
de inseguridad en la percepción de los sujetos? En este artículo se presentan algunos hallazgos que muestran, a través de un trabajo de recepción, los modos en que la información mediática de la inseguridad se imbrica en la vida cotidiana de los sujetos y con las distintas formas de percepción de los espectadores, de clasificación de la información, de interés cognitivo y de credibilidad en los medios cuando representan al delito.

Palabras clave: recepción, audiencias, noticias de inseguridad.

\section{ABSTRACT}

The media -specifically television - is identified as one of those responsible for the growing concern about insecurity. It is argued that if it exaggerates the enunciation of police news, with interests or intentions of generating fear, they are sensational. But, how do individuals interpret media when narrating 'insecurity'? Which social senses overlap in decoding media narratives about urban crime? This article covers tensions around how media information about insecurity overlaps individuals' daily lives and the audience's different perceptions, classification of information, cognitive interest, and credibility when the media represent crime. The perspective leading us was a historical and cultural understanding of the news consumption phenomenon, which sought to account for the different ways of appropriation of media discourse regarding 'insecurity'.

Keywords: Media consume, audience, crime news.

\section{RESUMO}

Os meios de comunicação - especificamente a televisão- são assinalados como um dos responsáveis da crescente inquietude pela segurança. Sustenta-se que exageram na enunciação das notícias policiais, que têm interesses ou intenções em gerar medo, que são sensacionalistas. Mas, como interpretam os sujeitos aos meios quando representam "a insegurança” e como decodificam esta informação? Que lugar ocupam as notícias de insegurança na perceção dos sujeitos? Neste artigo apresentam-se alguns resultados que mostram, através de um trabalho de receção, os modos em que a informação mediática da insegurança se imbrica na vida cotidiana dos sujeitos e com as distintas formas de perceção dos espectadores, de classificação da informação, de interesse cognitivo, e de credibilidade nos meios quando representam ao delito.

Palavras-chave: receção, audiências, notícias de insegurança.

En este artículo me propongo presentar algunos avances de mi investigación acerca de las interpretaciones que realizan los sujetos de las noticias periodísticas delictivas y las interrelaciones de estos discursos con sus prácticas

$$
144
$$




\section{DISERTACIONES}

AVANCES

Comunicación indigena en América Latina

ISSN: 1856-9536

Doi: http://dx.doi.org/10.12804/revistas.urosario.edu.co/disertaciones/a.5244

Volumen 11, Número 2 / Julio-diciembre 2018

Versión PDF para imprimir desde

http://revistas.urosario.edu.co/index.php/disertaciones

cotidianas. Los medios de comunicación -específicamente la televisión- son señalados como uno de los responsables de la creciente inquietud por la inseguridad. Se sostiene que exageran en la enunciación de las noticias policiales, que tienen intereses o intenciones en generar miedo, que son sensacionalistas. Es cierto que en los últimos diez años hubo un aumento (en cantidad y espacio) de la representación mediática del delito, tanto en los medios gráficos como audiovisuales. El crecimiento cuantitativo fue acompañado por una transición cualitativa: la noticia policial tradicional se ha convertido en 'noticia de inseguridad' y adquiere nuevas características: generalización ("todos estamos en riesgo siempre y en cualquier lado"); fragmentación (un relato episódico de cada hecho, sin el contexto ni las causas generales); una creciente centralidad en las víctimas, frente a lo cual el debate sobre la criminalidad adquiere una fuerte emocionalidad; una figura que se repite como objeto de temor, el delincuente joven varón y pobre; y la construcción de 'olas o modas delictivas' (un tipo de delito que parece en cada momento ser el más frecuente, pero que cuando se controla con los datos objetivos no suele haber variado mucho en su ocurrencia) (Kessler y Focás, 2014). Pero no sabemos de qué modos estas narrativas inciden en la vida cotidiana de quienes las reciben a través de distintos dispositivos mediáticos. Algunas preguntas que guiaron el trabajo fueron ¿cómo interpretan los sujetos a los medios cuando hablan de 'la inseguridad' y cómo decodifican la información sobre el delito urbano? ¿Qué lugar ocupan las noticias de inseguridad en la percepción de los sujetos? ¿Qué usos le dan los telespectadores a este tipo de información?

En este trabajo sigo la definición de inseguridad de Kessler y Merklen (2013), para quienes en el mismo concepto se imbrican las llamadas seguridad "objetiva" y "subjetiva", algo que de algún modo demostraría el caso argentino, donde, pese a una cierta disminución de las tasas de delito en los últimos años, no hubo un aumento de la aceptabilidad, o de un umbral de riesgo aceptable de la vida social. Es decir, me centro solo en una parte de los delitos, aquellos que en la opinión pública se engloban dentro de la idea de 'inseguridad'. Se trata de delitos que son percibidos como amenazas sobre los bienes y sobre las personas cuya característica común es la aleatoriedad, es decir, la percepción de que pueden abatirse sobre cualquiera.

Para abordar estos interrogantes, mi interés se asienta en dos áreas de estudios: los estudios de recepción de medios y la sociología del delito. Para indagar en estas preocupaciones, recurrí a distintas teorías que lograron abordar la multidimensionalidad de mi objeto. Por un lado, desde una perspectiva comunicacional, tomé nociones de los estudios de recepción y de los estudios culturales, que me permitieron reflexionar acerca de las apropiaciones de sentido que realizan los sujetos con lo que miran, oyen o leen en los medios de comunicación, y cómo articulan estos discursos en su vida cotidiana. En la recepción, operan multiplicidad de variables (sobre formaciones socioculturales previas) que producen el sentido final que le es otorgado a cualquier discurso mediatizado. Si bien este señala los caminos para una lectura preferencial, sugiere o demarca un sentido dominante, el público pone en juego sus conocimientos, sus ideas, sus prejuicios y sus emociones, es decir, realiza lecturas situadas en contextos culturales diversos que llevan finalmente al cierre del sentido. Los distintos ámbitos en los que los individuos actúan y a los cuales pertenecen brindan diversas y particulares competencias culturales y son los propios marcos conceptuales los que salen al encuentro del texto-mensaje en el momento de la relación con los medios (Hall, 1993; Martín-Barbero, 2006; Silverstone, 1996; Rodríguez, 2014). En palabras de Martín-Barbero, hay que reconocer que los medios no son omnipotentes, y que conjuntamente desarrollan múltiples interacciones influenciadas tanto por el referente mediático como por otras fuentes de mediación de la audiencia, sus variados procesos de recepción y sus contextos. Por otro lado, los estudios de la sociología del delito me permitieron 


\section{DISERTACIONES}

AVANCES

Comunicación indigena en América Latina

ISSN: 1856-9536

Doi: http://dx.doi.org/10.12804/revistas.urosario.edu.co/disertaciones/a.5244

Volumen 11, Número 2 / Julio-diciembre 2018

Versión PDF para imprimir desde

http://revistas.urosario.edu.co/index.php/disertaciones

conceptualizar nociones como el temor al delito, el riesgo y la construcción de la inseguridad en el marco de las sociedades contemporáneas. También recuperé de esta literatura cuestiones vinculadas con la prevención situacional y social del delito, la gestión de la seguridad en el entramado urbano y el tratamiento del tema en la agenda política (Kessler, 2009; Sozzo, 2011; Míguez e Isla, 2010).

\section{¿Audiencias o públicos?}

El recorrido analítico que proponemos por distintas teorías y conceptos se vincula con la búsqueda sobre el modo en el que la información mediática de la inseguridad se imbrica en la vida cotidiana de los sujetos y con las distintas formas de percepción de los espectadores.

Al interesarme por las percepciones de la seguridad que se configuraban en relación con los medios de comunicación y, de este modo, vincularme con los estudios de recepción, fue necesario centrarme en una discusión clave dentro de este campo de estudios basada en la distinción conceptual entre audiencias y públicos. Las configuraciones de sentido que arrastra cada uno y la elección, en ese sentido, de un abordaje teórico metodológico productivo fueron claves en el desarrollo de la investigación. Los análisis de audiencias y de públicos, si bien se mueven dentro del mismo campo semántico, se trazan sobre diferentes cuerpos teóricos, aunque no refieren a realidades completamente separadas. En pocas palabras, el concepto de audiencias remite al ámbito privado, a las investigaciones cuantitativas de mercado y a los estudios clásicos de recepción. Mientras que el de públicos, en la mayoría de los casos, refiere a actores colectivos involucrados en procesos políticos y culturales, y en ese sentido esa definición resulta fructífera en este estudio. Para Dayan (2005), los públicos están interesados en asuntos (issues) y no en situaciones particulares, y son actores fundamentales en el 'establecimiento de la agenda', lo que el autor define como la "conducción de la atención pública”. En ese orden de ideas, el público para constituirse como tal necesita antes ser audiencia, por tres razones: 1 ) cuando responde a un asunto, se trata de situaciones mediadas a las que está expuesto como audiencia, 2) necesita de los medios para llegar a más miembros y 3) las destrezas necesarias para convertirse en público no se adquieren sino en los medios (Dayan, 2005). Por lo tanto, de diferentes maneras, los medios de comunicación son cruciales para los públicos de hoy en día (y para las audiencias) en invitar, dar forma y administrar la focalización de la atención general y, por lo tanto, la construcción de las ficciones colectivas a través de las cuales los públicos llegan a ser, actúan y, finalmente, mueren (Livingstone, 2005).

Desde esta perspectiva teórica, en este artículo, me propongo sistematizar las percepciones de los entrevistados en relación con la construcción de la inseguridad como un asunto estable en la agenda mediática de los últimos diez años. Si bien no hay acuerdo entre estudios que muestren una relación directa entre la relevancia que los medios le otorgan a las noticias relacionadas con la delincuencia y el aumento del temor ciudadano, sí hay consenso en que los medios contribuyen a crear una agenda social sobre delitos existentes y riesgos posibles (Tyler y Cook, 1984; Altheide, 1997; Martini y Pereyra, 2009; D’Adamo, García Beaudoux y Freidenberg, 2007). Este escenario permite inferir, a modo de hipótesis, que la alta exposición mediática de lo criminal y de lo inseguro podría tener alguna incidencia en la expansión del sentimiento de inseguridad, siempre que exista una 'consonancia intersubjetiva', es decir que aquello que aparece en los medios tenga algún tipo de confirmación con lo que las personas perciben a su alrededor y amplifique el temor $u$ otros sentimientos (Kessler, 2009). 


\section{DISERTACIONES}

AVANCES

La percepción de la inseguridad que la opinión pública construye no solo tiene lugar a través de la experiencia personal o de la información que se transmite mediante las redes de comunicación interpersonal, sino también está íntimamente relacionada con lo que los medios de comunicación transmiten. ${ }^{1}$ La percepción del delito y de la inseguridad es influenciada tanto por el lugar que ocupa el tema en la agenda establecida por los medios como por el modo en que se realiza la cobertura del delito (D’Adamo y García, 2003). En este artículo, entonces, se abordará este aspecto, es decir, el rol de los medios de comunicación de masas en las percepciones de la inseguridad, en una mirada desde la recepción.

\section{Principales lineamientos del trabajo de campo}

Para este trabajo, en una primera aproximación al tema, se implementó una metodología combinada. Por un lado, relevamos durante tres meses del año 2012 y del año 2014 (febrero, marzo y abril) las coberturas de hechos delictuosos en los principales noticieros que se emiten en horario central, es decir, entre las 20 y las 23 , y que cuentan con mayores niveles de rating: Telenoche y Telefe Noticias. También destacamos las principales noticias policiales que se emitían en las dos cadenas de noticias de la televisión por cable que cuentan con mayor rating: TN y C5N. ${ }^{2}$ Este mapeo previo nos permitió conocer las representaciones vigentes en la agenda mediática policial. Con fines prácticos, centramos la investigación en la televisión, sin restar importancia a la radio, la prensa gráfica e internet, ya que en la actualidad consideramos al consumidor informativo como multimediático. ${ }^{3}$

En una segunda instancia, realizamos 30 entrevistas en profundidad semiestructuradas a adultos de entre 30 y 50 años de edad, pertenecientes a sectores de clase media. La selección de participantes se hizo a partir de

1 Desde otra perspectiva teórica, los trabajos de Gerbner y su equipo mostraron la correlación entre mayor audiencia de televisión y el sentimiento de vivir en un mundo mezquino y riesgoso. La teoría del cultivo postula entonces que la experiencia indirecta adquirida desde el consumo televisivo suplanta muchas veces a la experiencia directa como fuente primaria para el desarrollo de las creencias sociales. A partir de este punto de vista, se intentó delimitar las consecuencias que producen los mensajes televisivos no intencionales y destinados a un público masivo, y que cultivan en los televidentes ciertas asunciones básicas acerca de la realidad social y su funcionamiento. Se presume que cuanto más se exponga un individuo a la televisión, más también se parecerá su propia visión de la realidad a la presentada por ella. Con todo, no es un efecto mecánico: estos estudios también subrayan el imperativo de resonancia: el efecto de la TV es amplificado cuando la experiencia personal es similar a la que se ve en la Tv. En este sentido, y a partir de nuevas investigaciones, una de las tesis más importantes de Gerbner es la que indica que el principal efecto de la exposición a la violencia mediática no es tanto el incremento de los comportamientos agresivos, sino la profundización de las sensaciones de victimización, de riesgo y vulnerabilidad personal.

2 Este relevamiento fue realizado a modo de mapeo, y para ello accedimos a las grabaciones de los noticieros, que seguimos al menos durante tres días semanales. La intención no fue efectuar un análisis de contenido de las noticias, sino conocer las noticias delictivas que se emitieron durante ese período. Esta tarea fue de suma utilidad para llevar a cabo el trabajo de campo.

3 Según la última encuesta de la Secretaría de Medios de Comunicación de la Nación (2006), el 75,4\% ubica a la televisión como la principal fuente de información, pero siempre con diferentes combinaciones multimediáticas (radio, internet, prensa gráfica). 


\section{DISERTACIONES}

AVANCES

los datos del último informe de victimización del gobierno de la ciudad de Buenos Aires (2007), que nos llevó a trabajar en una comuna con altos índices de temor al delito: la 12, que aglomera los barrios de Coghlan, Saavedra, Villa Pueyrredón y Villa Urquiza. ${ }^{4}$ Específicamente, y a modo de recorte, trabajamos en las zonas centrales de los barrios de Villa Urquiza y Saavedra.

Los entrevistados fueron contactados al azar (dentro de los parámetros ya especificados) y en algunas ocasiones la misma persona que había sido entrevistada funcionaba como nexo con el próximo participante, que debía reunir las mismas condiciones. Como es habitual en estas investigaciones, se evitó convocar a familiares directos o amigos, pues entendemos que la mirada de un entrevistador cercano puede desviar o entorpecer la fluidez y sinceridad de las respuestas. La técnica de recolección de datos aplicada fue la entrevista en profundidad (personal, semiestructurada), que Marradi et al. (2007) definen como "una forma especial de conversación entre dos personas, dirigida y registrada por el investigador con el propósito de favorecer la producción de un discurso conversacional continuo y con cierta línea argumental por parte del entrevistado, acerca de un tema de interés definido en el marco de la investigación" (p. 216).

A partir de este primer acercamiento, indagamos en cuestiones vinculadas con distintas dimensiones de la percepción de la inseguridad en relación con el consumo de medios, las cuales se exponen a continuación. Para ilustrar, elegimos fragmentos de uno o dos ejemplos paradigmáticos, con el propósito de presentar los ejes centrales de los relatos sobre cada temática. Las representaciones delictivas de los noticieros fueron el disparador que utilizamos para analizar las percepciones de la seguridad que se conformaban mediante la práctica de mirar televisión (y en este grupo también incluimos los que funcionan como cadenas de noticias de 24 horas). No obstante, sabemos que las audiencias consumen a la vez otros géneros televisivos vinculados con el delito, como programas políticos, series de ficción o realities shows de policías, con lo cual, aunque nuestra mirada se circunscribe a un solo género, no desestimamos las referencias a otro tipo de emisiones.

Las noticias que funcionaron como disparadores fueron de distintos tipos de delitos, como 'entraderas', 5 'salideras', ${ }^{6}$ robos a mano armada, asaltos, y de algunos casos paradigmáticos, como el de Carolina Píparo.

A continuación, entonces, expongo algunos hallazgos sobre las interpretaciones de las noticias de inseguridad en los medios en torno a cuya elucidación se organizó este campo de estudio, y que fueron sometidas a revisión

4 Si bien no se han realizado hasta la fecha encuestas oficiales de este tipo, algunos organismos han indagado sobre el tema y arrojan datos más actuales. El Laboratorio de Investigaciones sobre Crimen, Instituciones y Políticas (LIIIP) de la Universidad Torcuato Di Tella elabora todos los meses un índice de victimización sobre una muestra promedio de mil casos a lo largo de las distintas regiones del país. Los últimos datos, de enero de 2015, indican que el $37,5 \%$ de los hogares, en 40 centros urbanos del país, fue víctima de al menos un delito en los últimos doce meses. Este índice se incrementó 1,1 puntos porcentuales en relación con el registro de enero de 2014.

5 En los medios de comunicación se acuñó el término 'entraderas' a la modalidad delictiva de robo que se produce al entrar a un lugar.

6 En los medios de comunicación se acuñó el término 'salideras' a la modalidad delictiva de robo que se produce al salir de un lugar.

7 Carolina Píparo estaba embarazada de ocho meses cuando el 29 de julio de 2010 fue atacada por un grupo de delincuentes en una salidera bancaria. Para robarle el dinero, le pegaron un tiro en la boca, lo que terminó con la vida de su bebé. Ella logró sobrevivir tras más de un mes de internación en un hospital de La Plata. 


\section{DISERTACIONES}

AVANCES

con el recurso de la perspectiva cualitativa. Estas aproximaciones pueden tomarse como tendencias del consumo de la información delictiva en dos dimensiones: la pregnancia de las noticias de inseguridad y la incidencia de las llamadas en la jerga periodística 'olas de inseguridad'.

\section{Las interpretaciones mediáticas frente a las 'olas de inseguridad'}

Una modalidad que se volvió recurrente en la representación de las noticias policiales en los últimos diez años es enmarcar al delito en cuestión en una línea serial de casos similares, que es presentada por los noticieros y las cadenas de noticias 24 horas como 'olas de inseguridad'. Esta operación discursiva también es utilizada en los diarios, la radio y los medios on line, que construyen mediante la edición la percepción de que ese caso no es aislado, sino bastante recurrente. Esta característica, propia de la transición de la noticia policial en noticia de inseguridad, es realzada mediante el uso de cintillos (en la prensa gráfica) o del zócalo (en audiovisual) que actúan como 'organizadores cognitivos'.

Fernández Pedemonte (2010) caracteriza a la ola de violencia como un tipo de caso mediático conmocionante que rompe con las rutinas de producción, circulación y recepción de las noticias, junto con el acontecimiento mediático y el escándalo mediático. ${ }^{8}$ La ola de violencia, define, "almacena varios acontecimientos violentos en paquetes de noticias, que se distribuyen a lo largo del ciclo de vida de la agenda de la información [...] se da cuando un tipo de delito reclama la atención de los editores de forma privilegiada, relegando la cobertura informativa de delitos de otro tipo" (p. 74). El investigador muestra cómo se articula desde los medios este mecanismo discursivo, ejemplificando con una 'ola de violaciones' en la ciudad de Buenos Aires, según el diario La Nación entre enero y marzo de 2004.

El diario no distingue entre abusos sexuales de un tipo o de otro y enlaza las noticias mediante el adjetivo 'otro' ("otro caso", "otra menor violada") o mediante una volanta que alude a 'delitos sexuales' [...] Durante el mes de marzo además, La Nación publicó estadísticas de denuncias de violaciones ("Se denuncia una violación cada 48 horas", titula el 7 de marzo), cuyos datos, sin embargo, no pertenecen a 2004, sino a 2003. Publicadas en el contexto de una ola de violaciones, esas estadísticas refuerzan la percepción de inseguridad, aunque en el texto se aclare que las denuncias de delitos sexuales registradas en enero de 2004 fueron menos que las de enero de 2003 (p. 104).

Así las cosas, para Fernández Pedemonte, la acumulación de noticias sobre un mismo tipo de delito que absorbe la atención de la sección de noticias policiales, el enlace de las diversas noticias sobre el mismo tipo de delito, la anexión de notas con estadísticas o sondeos de opinión, el 'rebote' de esta información de un medio a otro y los pedidos de opinión sobre el asunto a expertos por parte de los medios alteran el clima de opinión dentro del cual tienen que actuar los poderes del Estado (p. 105).

8 Dayan y Katz (1992) reservan la denominación de acontecimiento mediático para los eventos no rutinarios que demandan la interrupción de la programación televisiva regular, que son transmitidos en directo y que aferran la atención de gran cantidad de espectadores. Los escándalos mediáticos consisten en derrumbes de la reputación de personas públicas, provocadas por la trasgresión a la moralidad estándar, como el provocado por el presidente Richard Nixon en Watergate, o Bill Clinton con el affaire con Mónica Lewinski. Para más detalles, ver Fernández Pedemonte (2010). 


\section{DISERTACIONES}

AVANCES

De esta manera, entendemos que la cobertura mediática de los casos de inseguridad presentada en forma de 'olas' da lugar a encuadres que amplifican la presencia de ese hecho en los medios, generando, de algún modo, presión en los actores políticos para que actúen al respecto.

Para trabajar este tema, emitimos durante las entrevistas dos noticias presentadas como 'olas de inseguridad' en la ciudad de Buenos Aires. La primera pertenecía al canal de noticias C5N y alertaba sobre el nuevo raid delictivo de las 'entraderas' en algunos barrios, mostrando imágenes de cámaras ocultas sobre el modus operandi de los delincuentes. ' La otra, del canal tn, trataba sobre las 'salideras bancarias', presentada como una nueva modalidad delictiva. ${ }^{10}$ En este sentido, encontramos que, en los entrevistados, se generan dos tipos de percepciones frente a la emisión de los informes que presentan las noticias policiales enmarcadas de esta forma.

Por un lado, cuando la 'ola de inseguridad' en cuestión sucede en su mismo barrio, se activa un efecto de temor, o quizá de preocupación. En ese caso, nuevamente operaría una "presión ecológica” ${ }^{11}$ o de victimización anticipada, ya que los entrevistados reconocían que la cercanía les dificultaba poner en cuestión la información, como cuentan Teresa y Daniel, vecinos de Villa Urquiza:

La verdad no les creo mucho a los noticieros cuando hablan de olas, siempre pienso que exageran un poco... pero cuando alertan muy seguido sobre algún delito por mi zona, y dicen que pasa reiteradas veces, como en el caso de las entraderas, estoy más precavida sobre el tema (Teresa, 42 años).

Las olas, las modas, ahora son como una sección fija en los noticieros. A veces dicen que está armado, pero sí es cerca de mi barrio algo me provoca... por lo menos salir a hablar con los vecinos y ver si es verdad lo que están diciendo, estar más alerta (Daniel, 48 años).

Pablo, otro entrevistado, dice que, a pesar de que le parece extraño, no le resta atención a las noticias que vienen 'empaquetadas': "Qué sé yo, ahora están de moda las 'entraderas', y uno dice, bueno, cómo puede ser que de repente tantas... pero igual me hizo tomar conciencia... en mi edificio no hay seguridad, y ahora estoy más atento, no dejo pasar a nadie atrás de mí si no tiene llave, por ejemplo".

Otra cuestión relevante fue la manifestación de algunos entrevistados de una clara convicción sobre el 'hacer de los medios', es decir, la visualización de los periodistas como constructores de una realidad en pos de intereses particulares. Así, las noticias sobre inseguridad que son presentadas en la forma de 'ola' son identificadas y calificadas como un 'artificio', un 'invento', o con una clara intencionalidad política.

Es decir que estos entrevistados desconfían de los informes de inseguridad que presentan enmarcados los noticieros o las cadenas de noticias, en los que muestran 'la moda' de un determinado tipo de delito. La rubricación (en los zócalos o cintillos) con títulos como 'salideras bancarias', 'entraderas', 'raid de motochorros', 'secuestros express', que funcionan como frames, ${ }^{12}$ genera aún una mayor desconfianza, tal como manifiesta Sofía, de 45

9 http://www.youtube.com/watch?v=MgT-pf56LBM

10 http://tn.com.ar/policiales/bancos-en-la-mira_007781

11 Sebastian Roche propuso la hipótesis de una cierta "presión ecológica" para explicar que cuantas más personas victimizadas hay en una ciudad o en una zona, más información sobre estos hechos circula y se intensifica la preocupación, más allá de haber sufrido o no un delito personalmente (Kessler, 2009).

12 El framing o los frames sirven para el análisis en una única etapa, mientras que otros consideran que atraviesa todo el proceso comunicacional, en tanto pueden ser localizados en el comunicador, el texto, el receptor y la cultura (Entman, 1993). En otras palabras, encuadrar es definir problemas: diagnosticar sus 


\section{DISERTACIONES}

AVANCES

Comunicación indigena en América Latina

ISSN: 1856-9536

Doi: http://dx.doi.org/10.12804/revistas.urosario.edu.co/disertaciones/a.5244

Volumen 11, Número 2 / Julio-diciembre 2018

Versión PDF para imprimir desde

http://revistas.urosario.edu.co/index.php/disertaciones

años, que vive en el barrio de Saavedra: "Exageran, creo que se pone determinada noticia de moda y están todos los medios con lo mismo. Buscan similares para agrandar o seguir con el mismo tema, y es obvio que manipulan la información".

Cuando las noticias son presentadas bajo la figura mediática de 'olas', se pone en cuestión 'lo real' del acontecimiento, tal como manifiesta Leandro, un contador que vive en Villa Urquiza:

Ahí te das cuenta... este tipo de notas las hacen para rellenar... Esto es forzado y te das más cuenta, bah al menos yo me doy cuenta. Eso sí me parece que no es real, le prestó menos atención, porque ahí si ellos buscan confirmar algo de lo cual parten. Es el tipo de inseguridad que se pone de moda. Filtran todo el resto y lo demás no te lo muestran. Inventan, por ejemplo, que ahora hay más violaciones en Recoleta, eso sí que es mentira, no es que ahora hay más violaciones que el mes pasado, sino que ahora me están filtrando lo otro... Nunca compro la ola, sé que eso es un invento periodístico. Porque no puede ser tanta casualidad que un mes esté de moda un tipo de delito, otro mes otro, eso sí que es un invento periodístico.

Otro análisis interesante que surge en la percepción de los espectadores más jóvenes que entrevistamos (entre 30 y 40 años) a partir de este tipo de informes es que, aunque reconocen que los medios construyen la noticia, les preocupa, como explican en estos testimonios, que, "si los periodistas buscan casos para armar una ola, los encuentran".

Ninguno de esos casos me parece que sea inventado, es ir a buscarlos. No creo, por ejemplo, que a partir del caso Píparo empezaron a robar en todos los cajeros y que hubo más salideras bancarias, eso no me lo creo. Esas cosas suceden siempre de forma equilibrada, lo cual es terrible porque cuando los noteros buscan determinados tipos de delitos, con el fin que sea, encuentran un montón (Nicolás, 37 años).

Me parece que los medios tienen que representar lo que pasa en la realidad y, por lo tanto, lo de la inseguridad lo están dando en cuantía, en volumen, en lo que quieras... ¿Y de dónde sacan más y más casos de lo mismo? Un poco exagerarán, le agregarán sal y pimienta, pero evidentemente tienen mucho material de donde tomarlo (Candela, 31 años).

A partir de estos testimonios, es interesante notar cómo en estos entrevistados más jóvenes, a pesar de ser más cautos o menos crédulos sobre las operaciones mediáticas, igual se incrementa su temor. También puede aparecer un efecto de temor porque la ola pueda avanzar a otros lugares. En el interior del país, Kessler encuentra que la recurrente figura mediática de la 'ola de inseguridad' genera inquietud por su probable desplazamiento, "porque la policía 'corra a los ladrones' y se vayan al interior en busca de 'nuevos lugares donde la gente no esté tan precavida' o porque prima la idea de un 'contagio', una suerte de degradación desde los centros mayores hacia la periferia” (p. 257).

En síntesis, tanto en los medios gráficos como audiovisuales las 'olas de inseguridad' atraviesan el cuerpo de los diarios, de las páginas policiales a las políticas, de las portadas a las editoriales. Así la selección inicial que instala la 'inseguridad' en la agenda tiene una capacidad de estiramiento y metamorfosis que hace que en medio de la psicosis colectiva, que también invade las redacciones, los casos parecidos se agrupen bajo la misma terminología como 'secuestrador', 'violador', o que un ajuste de cuentas entre grupos delictivos sea considerado un nuevo hecho de

causas o las fuerzas que lo crean, hacer juicios morales al evaluar los agentes involucrados, medir costos y beneficios, y sugerir soluciones, justificando un tratamiento y prediciendo sus resultados. 


\section{DISERTACIONES}

AVANCES

'inseguridad'. Se trata, como muestra Lorenc Valcarce (2005), de una "validación circular del discurso mediático por el discurso mediático" (cursivas del autor).

\section{La pregnancia de las noticias de inseguridad}

Otra de las primeras cuestiones que se buscó conocer fue la pregnancia mediática frente a las noticias de inseguridad. Con este fin, se les pidió a los entrevistados que señalaran delitos que recordaran se hubieran cometido recientemente en el país. De este modo, se aplicó una metodología específica que nos permitió vislumbrar el cruce entre la agenda mediática y la memoria, según el impacto en los públicos.

A la vez fuimos cotejando las respuestas con nuestro relevamiento previo sobre las emisiones de la agenda mediática en los últimos meses, para observar y analizar qué casos policiales habían logrado mayor pregnancia en los sujetos. En esta etapa entonces partimos de lo que podríamos llamar la recepción o la interpretación, para luego indagar en los nudos de sentidos que se conforman con la emisión a partir de la aleatoriedad de la memoria.

Este ejercicio nos orientó para elucidar la intersubjetividad mediática y, posteriormente, hipotetizar sobre la selección que habían realizado los sujetos entre los casos que más recordaban, y analizar si operaba algún mecanismo de afinidad o rechazo con las víctimas, o si otros elementos actuaban en el encuentro con la noticia. Se agregaron preguntas como ¿fue cerca de su casa? ¿Recuerda cómo se enteró? ¿Es su fuente de información habitual? ¿Lo leyó/escuchó en otro lado? ¿Lo comentó luego en su familia, en su trabajo, en la escuela? ¿Se acuerda qué comentarios se hicieron? ${ }^{13}$

Uno de los primeros avances fue que, al preguntar por delitos que recordaran de los últimos meses, cada persona nombraba los que se relacionaban con distintas dimensiones de su contexto personal. Es decir, si hacemos un balance de las respuestas, hallamos cierto acuerdo en que la cercanía con el lugar donde sucede el delito es determinante en la pregnancia de la audiencia. Muchos entrevistados reconocían hacer zapping cuando el noticiero emitía informes sobre distintos tipos de delitos, o pasar de largo las páginas de policiales de los diarios, excepto si el hecho había sucedido en su barrio, o en un vecindario cercano. Es decir que operaba una cierta 'presión ecológica', ya que la información sobre delitos en la zona actúa como anticipación de una eventual victimización personal y, por ende, es una fuente de temor. También si se trata de una zona donde vive algún familiar o conocido, tal como muestran los siguientes testimonios de vecinos de Saavedra:

Por mi barrio nunca vi nada raro, ni me pasó nada. Pero cuando veo en los medios que robaron en Saavedra, después me quedo unos días con miedo, sobre todo si ando seguido por la zona donde fue el robo (Lucas, 50 años).

13 Esta técnica metodológica fue adoptada luego de un intento que resultó fallido, que consistió en iniciar las conversaciones haciendo referencia explícita al rol de los medios de comunicación. En esos casos, notamos cierta reticencia de los entrevistados, e incluso una postura de intransigencia y negación a reconocerse como consumidores de ese tipo de información. El cambio implementado sobre el contenido de las preguntas nos permitió ingresar de un modo más sutil en las percepciones mediáticas de los sujetos en relación con la inseguridad y fue adoptada luego de corroborar que resultaba más funcional a los fines de nuestra investigación. 


\section{DISERTACIONES}

AVANCES

En una época en mi cuadra había salido la noticia de dos o tres violaciones, acá por mi barrio. Hace unos dos años, uno se había metido por un árbol, otro en la esquina, otro a la vuelta, y esa misma semana una noche escuché el grito de una chica, que no tuve tiempo de reaccionar y se terminó. No sé qué fue lo que estaba pasando, si la estaban violando, si le robaron, no sé. Pero esos días me daba mucho miedo salir, miraba para todos lados, desconfiaba de todos los hombres que me pasaban cerca... qué sé yo, después se me pasó (Pilar, 35 años).

En este último testimonio queda en evidencia la interrelación del texto mediático en la vida cotidiana, el cual se manifiesta en la subjetividad del sujeto-audiencia, que "escucha un grito a la noche" o "cree escucharlo" y lo asocia con un nuevo caso de violación en su barrio, tal como anunciaban los principales titulares mediáticos esa semana.

En el mismo sentido, los entrevistados recordaban información delictiva relacionada con algún aspecto de su vida personal. Muchos se identificaban con la víctima porque compartían el mismo oficio y/o profesión, otros por sus actividades de tiempo libre, también por el lugar que ocupaba en la estructura familiar. Entendemos que esta característica, que se repite en distintas entrevistas, se activa por un mecanismo de empatía con la víctima, como muestra José, un joven ingeniero y fotógrafo por vocación:

Ahora me acuerdo del caso del francés, que todo bien con el arte, pero yo me paro a sacar una foto en

la Torre de los Ingleses ni soñando... cuando lo vi en tN, me puse en el lugar del tipo unas 20 veces y me pregunté cómo hubiese reaccionado yo en su lugar. Y, la verdad, depende el humor de ese día, de cómo esté... no es que me sienta más o menos valiente, pero te da bronca. No soy de una clase social como para decir bueno me desprendo y después me compro otra cámara, ¿entendés? Hay días que digo y bueno si me vienen a afanar la largo, y otros días que no, que me está saliendo todo mal, y pienso yo a la cámara no la largo por nada.

Debido al interés del entrevistado por el caso (un francés fue asesinado de una puñalada en el pecho cuando un delincuente intentó robarle una cámara de fotos en el barrio de Retiro), buscamos en internet el video que emitió la cadena de noticias tn donde mostraban cómo había sido el arrebato (una cámara de seguridad captó el momento).

En este caso yo creo, por lo que se ve, que fue una confusión o un error del ladrón porque nosotros (NDR: por los fotógrafos) nos atamos la cámara, la correa acá en la mano (muestra cómo se hace) para evitar que se te caiga en realidad. Entonces yo creo que cuando el pibe tiró para afanarle, quedó enganchada y el hombre le tiró un codazo... pero no por resistirse. Aunque no hubo tiempo de explicaciones, porque el chico tenía un arma y reaccionó.

Notamos que el entrevistado, en su interpretación, se identifica con la víctima por su vocación (ambos son fotógrafos amateurs) e intenta trasladarse a la misma situación. Incluso no hace mención a ninguna de las demás características de la persona que fue apuñalada, como ser su condición de extranjero, hombre mayor, etc., pero sí trata de 'ponerse en su lugar' de fotógrafo y ensayar sus posibles reacciones.

En otros casos, la empatía tiene lugar por características de género, como comenta esta entrevistada que está esperando su primer hijo.

El caso de Carolina Píparo me marcó, lo pienso todo el tiempo, pienso todo el tiempo que puedo ser ella.

Cuando me enteré no me dio miedo... me generó lo mismo que cuando hay un hecho de violación o de

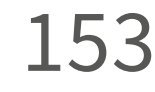




\section{DISERTACIONES}

AVANCES

Comunicación indigena en América Latina

ISSN: 1856-9536

Doi: http://dx.doi.org/10.12804/revistas.urosario.edu.co/disertaciones/a.5244

Volumen 11, Número 2/ Julio-diciembre 2018

Versión PDF para imprimir desde

http://revistas.urosario.edu.co/index.php/disertaciones

abuso que decís "qué hijo de puta, cómo podés dispararle a una mina que encima está embarazada, o atacarla sexualmente cuando sabés que sos más fuerte", me da mucha impotencia cuando veo esos casos, a veces hasta cambio de canal... (María, 36 años).

Observamos que se establece un movimiento donde algunos de los entrevistados, al consumir la noticia, se trasladan imaginariamente a la situación que experimentó la víctima del delito. Aquí también la empatía con alguna característica de la posición del sujeto funciona para situarse una y otra vez en el lugar de la víctima y en esa configuración interactúan distintos sentimientos y emociones.

Por su parte, la modalidad enunciativa de las noticias señala la existencia de un contrato de lectura que buscar obtener el reconocimiento del receptor. La víctima aparece como representante de los sectores medios: sus características remiten a las de cualquier 'ciudadano común', por lo tanto, pudo haberle pasado a cualquiera. En palabras de Garland, la víctima, tal como la representan los medios, surge como un personaje representativo cuya experiencia se supone común y colectiva (en ciertos sectores sociales) en lugar de individual y atípica. El lenguaje inmediato del relato mediático "se dirige directamente a los miedos y la ira de los espectadores, produciendo efectos de identificación y reforzamiento que son usados política y comercialmente” (2005, p. 242).

En estas líneas nos acercamos al modo en que los sujetos entrevistados fijan la atención y la memoria sobre las noticias de inseguridad. De esta manera, pudimos notar que la recepción está atravesada por distintas mediaciones, principalmente, identitarias -edad, género, clase social- (Orozco Gómez, 1996), pero también mediaciones en relación con la profesión, los grupos de pertenencia y el contexto social del barrio donde viven. Por último, otra de las características sobresalientes fue la incidencia de la cercanía con el lugar donde se cometió el crimen, que los medios remarcan y promueve distintas influencias en los entrevistados.

\section{Elementos de cierre}

El recorrido propuesto en este artículo tuvo como objetivo acercarnos a una primera exploración acerca de las percepciones de la inseguridad que se configuran en relación con las noticias delictivas. Con este fin, en primer lugar, se realizó un trabajo de recepción exploratorio en dos barrios de la Ciudad Autónoma de Buenos Aires con alta percepción del temor al delito.

De este modo, en los distintos apartados trabajamos, entre otras cuestiones, acerca de la victimización indirecta que ejercería la televisión, en tanto soporte con más audiencia de este tipo de información, la pregnancia de las noticias delictivas, y las interpretaciones mediáticas frente a las llamadas 'olas de inseguridad'. Sin embargo, más allá de estos hallazgos, consideramos que es poco realista señalar a los medios como culpables del aumento del sentimiento de inseguridad. Partimos de considerar a los medios como constructores de la realidad social, que coproducen sentidos frente a públicos críticos. Es decir que, para que los medios tengan incidencia en los públicos, tiene que existir lo que Kessler denomina 'consonancia intersubjetiva', esto es, algún tipo de confirmación entre lo que los medios muestran y la experiencia cotidiana. En pocas palabras, para que los medios hagan sentir su influencia, tiene que haber algún tipo de relación entre la información mediática que reciben y lo que perciben en su vida cotidiana. Es decir, la clase social, la propia reflexividad como consumidor de noticias, las identificaciones de clase y de edad, y la relación entre lo que las noticias muestran y la percepción de la realidad circundante inciden en las variadas formas de recepción de los medios.

\section{4}




\section{DISERTACIONES}

AVANCES

En síntesis, este artículo pretendió llevar a cabo un acercamiento al modo en que los discursos mediáticos de lo inseguro se imbrican en la vida cotidiana, incidiendo muchas veces en la propagación de sentimientos o en la consolidación de creencias acerca del delito.

\section{Referencias}

1. Altheide, D. (1997). The news media, the problem frame and the production of fear. The Sociological Quarterly, 38(4), 647-668.

2. D’Adamo, O., \& García, V. (2003). ¿Distorsiona la prensa la percepción social que la opinión pública construye acerca del delito, la violencia y la inseguridad? Revista de Psicología Social, 18(1), 3-15.

3. D’Adamo, O., García Beaudoux, V., \& Freidenberg, F. (2007). Medios de comunicación y opinión pública. Madrid: McGraw-Hill.

4. Dayan, D. (2005). Mothers, midwives and abortionists: genealogy, obstetrics, audiences \& publics. En S. Livingstone (Ed.), Audiences and publics: when cultural engagement matters for the public sphere. USA: Intellect Books.

5. Fernández Pedemonte, D. (2010). Conmoción pública. Los casos mediáticos y sus públicos. Buenos Aires: La Crujía Ediciones.

6. García Beaudoux, V., \& D’Adamo, O. (2007). Tratamiento del delito y la violencia en la prensa. Sus posibles efectos sobre la opinión pública. En L. Luchessi \& M. G. Rodríguez (Comps.), Fronteras globales. Cultura, política y medios de comunicación. Buenos Aires: La Crujía Ediciones.

7. Garland, D. (2005). La cultura del control. Crimen y orden social en la sociedad contemporánea. Barcelona: Gedisa.

8. Hall, S. (1993). Encoding/decoding. En S. During (Ed.), The cultural studies reader (pp. 90-103).

9. Kessler, G. (2009). El sentimiento de inseguridad. Sociología del temor al delito. Buenos Aires: Siglo Veintiuno Editores.

10. Kessler, G., \& Focás, B. (2014). ¿Responsables del temor? Sentimiento de inseguridad y medios en América Latina. Revista Nueva Sociedad, 249.

11. Kessler, G., \& Merklen, D. (2013). Una introducción cruzando el Atlántico. En R. Castel, G. Kessler, D. Merklen \& M. Murard, Individuación, precariedad, inseguridad. ¿Desinstitucionalización del presente? Buenos Aires: Paidós.

12. Livingstone, S. (2005). On the relation between audiences and publics. En S. Livingstone (Ed.), Audiences and publics: when cultural engagement matters for the public sphere. usA: Intellect Books.

13. Lorenc Valcarce, F. (2005). El trabajo periodístico y los modos de producción de la noticia: el tratamiento de la inseguridad en la prensa argentina. Revista Question, 1(7).

14. Marradi, A., Archenti, N., \& Piovani, J. (2007). Metodología de las ciencias sociales. Buenos Aires: Emecé.

15. Martín-Barbero, J. (2006). Recepción de medios y consumo cultural: travesías. En G. Sunkel (Coord.), El consumo cultural en América Latina. Construcción teórica y líneas de investigación. Bogotá: Convenio Andrés Bello. 


\section{AVANCES}

16. Martini, S., \& Pereyra, M. (Comps.). (2009). La irrupción del delito en la vida cotidiana. Relatos de la comunicación política. Buenos Aires: Editorial Biblos.

17. Míguez, D., \& Isla, A. (2010). Entre la inseguridad y el temor. Instantáneas de la sociedad actual. Buenos Aires: Paidós.

18. Orozco Gómez, G. (1996). La oferta televisiva y su percepción por jóvenes de la Ciudad de México. Anuario Coneicc de Investigación de la Comunicación, (3).

19. Silverstone, R. (1996). Televisión y vida cotidiana. Buenos Aires: Amorrortu Editores.

20. Tyler, T., \& Cook, F. (1984). The mass media and judgements of risk. Journal of Personality and Social Psycology, 47(4), 693-708. 